United Kingdom, several reservations should be acknowledged. The basic design was simple but was augmented in several detailed ways that many of those working with medical audit advisory groups could find confusing. Nevertheless, this should not deter them from seeking to understand the conclusions. As the doctors in the groups were trainers it is reasonable to question whether the findings are generalisable to all general practitioners. The study, however, began an eventful 10 years ago, and today's practitioners have had ample time to catch up. Further reports from the study should help to clarify the difficulties encountered by the groups in devising standards. We need to understand how the groups agreed and accepted the use of standards in daily practice and how much support and training the group members required.

Improvement in outcome was confined to one condition, recurrent wheezy chest. The absence of any demonstrable effect on outcome for the other conditions is understandable given the chosen conditions. Acute episodes of cough or vomiting in children are most commonly caused by self limiting illnesses. Itchy rash and bedwetting are also symptoms rather than diagnoses, and for both the connection between care and its outcome is tenuous. Assessment of outcome is notoriously difficult, and its inclusion in audits of other than the simplest clinical procedure is unusual. Rather than regarding the study as a definitive assessment of the role of audit in improving outcome it should be seen as encouraging further research.

All methods that are used to improve the quality of care must be subjected to critical evaluation of their effects on outcome, and audit can be no exception. Audit has progressed since this study was planned in 1982, and it would be unwise to assume that feedback is relatively ineffective because the receipt of information about group performance did not lead to improvements. Recent work has shown that feedback of information about performance can facilitate change. ${ }^{5}$ During the past decade audit has also been brought closer to the place of work, the focus having changed from doctors meeting together in peer groups outside their practices to the incorporation of audit into the daily management of practice teams. Several reports have shown the value of audit in this context, when it is seen as a means to an end rather than an end in itself. ${ }^{67}$ The lessons from this study, however, still apply to standard setting in teams and to the attempts of medical audit advisory groups to initiate projects involving groups of practices.

This study gives helpful advice about implementing audit. Setting standards can improve the performance of the participants in terms of process and probably also of outcome. It is essential that those who use the standards have accepted them and the need for change. Standards that were received without these steps were not followed by improvements. Members of medical audit advisory groups and those leading practice teams will have to design their audits to ensure that participants have the opportunity to claim the standards as their own.

RICHARD BAKER

Director,

Eli Lilly National Medical Audit Centre,

Department of General Practice,

University of Leicester,

PO Box 65,

Leicester LE2 7LX

1 Maynard A. The case for auditing audit. Health Service fournal 1991;101:26.

Derry J, Lawrence M, Griew K, Anderson J, Humphreys J, Pandher KS. Auditing audits: the method of Oxfordshire Medical Audit Advisory Group. BMF 1991;303:1247-9.

3 North of England Study of Standards and Performance in General Practice. Medical audit in practice. I. Effects on doctors' clinical behaviour for common childhood conditions. BMF 1992; $304: 1480-4$

4 North of England Study of Standards and Performance in General Practice. Medical audit in practice. II. Effects on health of patients with common childhood conditions. BMf 1992;304:1484-8

Winkens RAG, Pop P, Grol RPTM, Kester ADM, Knottnerus JA. Effect of feedback on test ordering behaviour of general practitioners. $B M 7$ 1992;304:1093-6.

6 Hart JT, Thomas C, Gibbons B, Edwards C, Hart M, Jones J, et al. Twenty-five years of case finding and audit in a socially deprived community. BMf 1991;302:1509-13.

Marsh GN, Channing DM. Narrowing the health gap between a deprived and an endowed community. BMF 1988:296:173-6.

\title{
Thinking through a salaried service for general practice
}

\author{
It may eventually be inevitable
}

The General Medical Services Committee recently commented that previous arguments for and against a salaried service for general practitioners had been exaggerated. 'In the recent ballot of general practitioners most favoured a salaried option and more than $10 \%$ favoured a salaried service for all. ${ }^{2}$

Until now the idea of salaried general practice has never been accepted by a majority of general practitioners ${ }^{3}$ despite the fact that certain groups of general practitioners - in the armed services, in deputising services, and trainees-are salaried. ${ }^{\prime}$ Only the countries of the former socialist bloc opted for salaried doctors as their main front line service, and the poor record of these countries in developing integrated primary care ${ }^{4}$ combined with the collapse of their political and economic systems makes an east European style of salaried general practice an unappetising model.

American experience of salaried family doctors working in health maintenance organisations suggests that while there are advantages in integrating care, ${ }^{5}$ there are also opportunities for exploiting medical labour in profit driven organisations. ${ }^{6}$ In Britain most pressure for a salaried service has come from doctors working in deprived areas with high demands and poor facilities. ${ }^{7}$ The revised contract for general practitioners seems to have worsened the circumstances of some doctors, especially women, and has renewed the call for a salaried option. ${ }^{289}$

Although conceptual frameworks for evaluating the effectiveness of different ways of remunerating primary care doctors have been discussed, ${ }^{10}{ }^{11}$ there is only scanty empirical evidence from trials of a salary versus fee for service payment, ${ }^{12}$ and the results are equivocal. Why then did the representative body of general practitioners take this uncharacteristic and unprecedented step of opening debate about a salaried service at a time when the government is attempting to deregulate the NHS and create a mixed economy of health care? And why do so many general practitioners now respond favourably to the idea of a salary $?^{2}$

The answer lies in the political economy of general practice, which is a public sector franchise, rather like the network of sub-post offices that fills the spaces between the directly managed main post offices. Franchising is an economic system in which a central organisation lends its trading name 
and logistic support to locally owned outlets whose proprietors take the financial risks of trading..$^{13}$ In the NHS the Department of Health acts as a franchiser, getting a network of outlets at low cost and minimal risk, with a committed and stable professional workforce with extensive knowledge of local markets. As franchisees general practitioners get protection against risk (through cost rent schemes, NHS superannuation, and other forms of support); some element of managerial help; technical support (open access investigative services in local hospitals); local autonomy and everyday control of activity; and profits subject only to taxation under schedule D.

Franchising may be a form of organisation in which success is cloned rapidly at limited cost, and this may be one reason why the government is now seeking to shift hospitals and community services on to a franchise basis. But franchising has features that its advocates in general practice may not yet understand. ${ }^{13}$

To maintain a standardised product or service franchisers seek increasing control over franchisees as time passes and as the outlet network enlarges and becomes more complex in its activities. Unilateral modification of contracts by franchisers occurs, and the independence of the franchisee may be eroded by increasingly specific contractual obligations. A point may be reached where the franchisee has all the responsibilities of an employee but none of the rights-for example, paid maternity leave.

Finally, franchising may result in the rapid development of an industry that becomes too complex and too costly for local entrepreneurs to buy into and manage, so that the franchiser imposes its own management structure. The best example of this in Britain is McDonald's, which operates a franchise in the United States but mainly as a directly managed industry in Britain.

As the general practice franchise enlarges and takes on roles beyond the traditional function of gatekeeper its managerial capacity will be strained. Management skills among general practitioners are notoriously limited, and even in the extreme model of franchise, the fundholding practice, managerial skill is notable for its absence. ${ }^{1+}$ Franchisers spending increasing amounts in supporting the growing franchise operation will want ever better value for money and ever greater standardisation of service. If this is not forthcoming they will be tempted to take over completely. Elements of this may be emerging where inner city general practitioners opt to join community health trusts. ${ }^{15}$ At some future time, however, a primary care led NHS might enter a crisis of management and of service provision which will be solved through the direct control of general practice. The precedent exists in the speedy and easy conversion of the Swedish health service to one based on salaried status in $1970 .^{16}$

Equally, the ability of newcomers to general practice to buy into increasingly costly outlets may fall, so that group practices become dominated by a shrinking core of established principals with a peripheral group of salaried doctors working for them on a sessional basis. The American experience of youthful doctors passing through or getting stuck in salaried posts where clinical decisions can be distorted by the commercial considerations of the practice's owners $^{5}$ will then become relevant to us. Not only is the GMSC's decision to open debate about a salaried option less odd than it seems at first but it may indicate that general practice's negotiators are beginning to recognise necessity. The result of the ballot on Your Choices for the Future vindicates their decision.

STEVE ILIFFE

Senior Clinical Lecturer,

Department of Primary Health Care,

University College and Middlesex School of Medicine,

London

General Medical Services Committee. Your choices for the future. London: BMA, 1991.

2 Electoral Reform Ballot Services. Your choices for the future: a survey of GP opinion. London: General Medical Services Committee. 1992.

Honigsbaum F. The division in British medicine: a history of the separation of general practice from hospital care, 1911-1968. London: Kogan Page, 1979.

$4 \mathrm{McKee} M$. Health services in central and eastern Europe: past problems and future prospects. f E pidemiol Community Health 1991;45:260-5.

5 Relman AS. Salaried physicians and economic incentives. $N$ Engl f Med 1988;319:784.

6 Scovern H. Hired help; a physician's experience in a for-profit staff-model HMO. N Engl J Med 1988;319:787-90.

Robson J. Salaried service - a basis for the future? BMf 1981;283:1225-7.

8 Gibbons B. The case for salaried GPs. Health Services fournal 1991;101:10.

9 Medical Practitioners Union. A salaried service - why now, and how? London: MPU, 1991.

0 Pincus HA. Assessing the effects of physician payment on treatment of mental disorders in primary care. Gen Hosp Psychiatry 1990;12:23-9.

1 Kahn HS, Orris P. The emerging role of salaried physicians: an organisational proposal. $f$ Public Health Policy 1982;3:284-92.

2 Hickson GB, Altemeier WA, Perrin JM. Physician reimbursement by salary or fee-for-service: effect on physician practice behavior in a randomized prospective study. Pediatrics 1987;80:344-50.

14 Quinn G, Burns P. Survey of management control systems in general practice. London: Cranfield School of Management and Stoy Hayward, 199

15 Stanley I. Community NHS Trusts should take the lead. Medical Monitor 1991;4:14-5.

16 Brygren LO. Doctors on salary. Scand J Soc Med 1989;17:225-6.

\section{Warning signals from Oregon}

\section{The different dimensions of rationing need untangling}

The Oregon experiment has become part of the folklore of the NHS. If we want to see what the future holds for the NHS, it is argued, we need only look at what is happening in Oregon now. ${ }^{12}$ The role of the purchasers in the new style NHS means that they will have to decide what services to buy-or not to buy - on behalf of their populations. The implicit rationing that characterised the NHS in the past has to be made explicit: the responsibility for allocating scarce resources, previously largely diffused among clinicians, is now concentrated in the purchasing authorities. In turn, therefore, these have to choose between competing claims on resources and devise criteria that can be publicly justified. And if this is the shape of things to come where better to look for a model than Oregon-for Oregon has been engaged in precisely such an endeavour for the past three years.
In effect, Oregon has provided a laboratory in which techniques for devising rationing formulas have been tried out. The results of the experiment are therefore of great interest. Unfortunately, they are also ambiguous and difficult to interpret. So much is clear from a report of a symposium on the Oregon plan, organised and published by the Brookings Institution, which brings together the views of both the proponents and the critics of the initiative, medical and lay. ${ }^{3}$ This suggests that Oregon holds out a warning rather than offering a model for import into Britain: a warning that there are no ready made techniques for determining choices among competing priorities in health care.

In its origins the Oregon plan was an attempt to devise an appropriate package of health care for those covered by the state's Medicaid scheme, the safety net programme for the 